\title{
ENDOCRINOPATHIES IN THALASSEMIA PATIENTS
}

\author{
Umer Touheed, Samra Maryam*, Hafiz Muhammad Murtaza, Muhammad Mujtaba Sabir**, Lutfullah Goheer, Aamir Aslam Awan*** \\ Combined Military Hospital Multan/National University of Medical Sciences (NUMS) Pakistan, *University of Health Sciences, Lahore Pakistan, **Punjab \\ Institute of Cardiology, Lahore Pakistan, ${ }^{* * *}$ Combined Military Hospital Lahore/National University of Medical Sciences (NUMS) Pakistan
}

\section{ABSTRACT}

Objective: To determine the common endocrine complications found in children having thalassemia major.

Study Design: Cross-sectional study.

Place and Duration of Study: Department of Pediatric Medicine, Combined Military Hospital Multan, from May to Nov 2019.

Methodology: A total of 160 Children with thalassemia were taken in this study. Once registered, venous blood sample was taken and sent to the laboratory for endocrine profile. SPSS-21 was applied for analysis of collected data.

Results: Out of 160 study cases, 100 (62.5\%) were boys while 60 (37.5\%) were female patients. Mean age of our study cases was $8.58 \pm 1.98$ years. Mean duration of disease was $5.28 \pm 3.29$ years. Parental consanguinity was positive in 122 (76.3\%) and only 47 (29.4\%) were taking chelation therapy. Mean HbA1C level was $6.23 \pm 1.18 \% \mathrm{mg} / \mathrm{dl}$ and diabetes was noted in 41 $(25.6 \%)$ of our study cases. Mean FT4 was $0.98 \pm 0.13 \mathrm{ng} / \mathrm{dl}$ and hypothyroidism was noted in 24 (15\%) of our study cases.

Conclusion: Diabetes and hypothyroidism were the common endocrine complications noted in our study among children having thalassemia. All physicians treating such patients should always screen such patients for early diagnosis and timely management in order to reduce burden of related morbidities and enhance quality of life of these patients.

Keywords: Diabetes, Endocrine, Hypothyroidism, Thalassemia.

How to Cite This Article: Touheed U, Maryam S, Murtaza HM, Sabir MM, Goheer L, Awan AA. Endocrinopathies in Thalassemia Patients. Pak Armed Forces Med J 2021; 71(6): 1958-1961. ～Doi: https://doi.org/10.51253/pafmj.v6i6.4778

This is an Open Access article distributed under the terms of the Creative Commons Attribution License (https://creativecommons.org/licenses/by-nc/4.0/), which permits unrestricted use, distribution, and reproduction in any medium, provided the original work is properly cited.

\section{INTRODUCTION}

All types of thalassemias are a cluster of hereditary anemias owing to underlying genetic mutation leading to impaired hemoglobin production. The thalassemias are among the most common genetic disorders worldwide, occurring more frequently in the Mediterranean region, the Indian subcontinent and Southeast Asia. ${ }^{1}$ Versatile genetic makeup of different ethnic groups lead to variable tendency of developing various types of endocrine complications in thalassemia patients. Various combinations of underlying genetic mutations (heterozygous/homozygous) also influence this tendency of endocrinopathies in a certain group of population. Thalassemia's complications can be a result of many mechanisms. Most complications are caused by increased iron sedimentation in tissues like heart, endocrine glands and these results in heart failure, arrhythmia, hypothyroidism, diabetes mellitus and so on. ${ }^{2,3}$ A study has reported that $29.4 \%$ children with thalassemia had diabetes, $11.8 \%$ had hypothyroidism. ${ }^{4}$ A local study by Ibrahim et al, ${ }^{5}$ reported $13.8 \%$ hypothyroidism and $5.6 \%$ diabetes in children with thalassemia.

These types of endocrniological complications

Correspondence: Dr Hafiz Muhammad Murtaza, Department of Pediatric Medicine, Combined Military Hospital Multan Pakistan

Received: 11 Nov 2020; revision received: 26 Nov 2020; accepted: 27 Nov 2020 pose a great physical as well as psychological morbidity on life of these patients. Patients of thalassemia suffering from diabetes have poor glycemic control and more episodes of hypoglycemia than T2DM. Moreover $\mathrm{HbA} 1 \mathrm{c}$ is not a reliable parameter for glucose monitoring in patients with thalassemia leading to difficulty in monitoring. ${ }^{6}$

There should be high index of suspicion for endocrine dysfunction while monitoring patients of thalassemia as many of them can have subclinical hypoyhyroidism as reported in some studies. ${ }^{7-9}$

Impaired glucose control (pre-diabetic state) can be reversed by optimal iron chelation therapy. In the same way hypothyroidism can be prevented as hemosiderosis is the predominant pathophysiology leading to these endocrinological complications. ${ }^{6-9}$

This study will report current magnitude of the problem of endocrinological complication in children with thalassemia which will help us to treat these complications followed by early diagnosis of these endocrinological derangements. This will lead to the appropriate management of these patients which will decrease disease related morbidity, improve quality of life of these patients and also decrease extra healthcare costs of hospital authorities. We have focused on common endocrinopathies encountered in our population in comparison with others. 


\section{METHODOLOGY}

This cross-sectional study was conducted at paediatrics department in Combined Military Hospital Multan, from May to November 2019. A total of 160 children suffering from thalassemia were taken in this study. Once registered, venous blood sample $(5 \mathrm{ml})$ was taken for performing tests of endocrine profile in the pathology laboratory of the hospital. Sample size $(\mathrm{n}=160$ cases) was calculated by using following formula; $\mathrm{n}=\mathrm{z} 2 \mathrm{pq} / \mathrm{d} 2$ ( $\mathrm{z}=1.96, p=11.8 \% 4$ (frequency of hypothyroidism), $\mathrm{q}=100 p, \mathrm{~d}=5 \%$. Non probability consecutive sampling technique was used. Proper permission was taken from Institutional Ethical Committee to conduct this study.

Inclusion Criteria: Children of both genders having thalassemia major with age ranging from 5-12 years were enrolled from Thalassemia centre, Combined Military Hospital, Multan.

Exclusion Criteria: Patients already diagnosed or on treatment for hypothyroidism and diabetes were excluded from the study.

After informing patients and their parents about goals of study, informed written consent was taken. Strict confidentiality was ensured during data gathering and analysis. Baseline information like age groups, gender, chelation therapy, no. of transfusions/month, disease duration, parental consanguinity, residential status and maternal literacy was recorded.

All the data was formulated and entered in SPSS21 for analysis. Mean and standard deviation were calculated for the age, FBS and FT4 by descriptive statistics. Frequencies and percentage were tabulated for the categorical variables like gender, age groups, parental consanguinity, chelation therapy, endocrine complications. Chi-square test was applied to see its effect on results. The $p$-value of $\leq 0.05$ was considered as significant.

\section{RESULTS}

There were a total of 160 patients meeting inclusion criteria of our study. Of these 160 study cases, $100(62.5 \%)$ were male while $60(37.5 \%)$ were female patients.

Mean age in our study cases was $8.58 \pm 1.98$ years (with minimum age of 5 years and maximum age of 12 years). Mean age of our male patients was $8.63 \pm$ 1.99 years while that of female patients was $8.50 \pm 1.97$ years $(p=0.689)$. Majority of our study cases i.e. 130 $(81.3 \%)$ were aged up to 10 years. Mean duration of disease was $5.28 \pm 3.29$ years and $136(85 \%)$ had disease duration for more than 2.5 years. Parental consanguinity was positive in $122(76.3 \%)$ and only $47(29.4 \%)$ were taking standard chelation therapy (Table-I). While 136 $(85 \%)$ had to undergo blood transfusion up to 2 times per month.

\begin{tabular}{|c|c|}
\hline Variables & Frequency (\%) \\
\hline \multicolumn{2}{|l|}{ Gender } \\
\hline Male & $100(62.5 \%)$ \\
\hline Female & $60(37.5 \%)$ \\
\hline \multicolumn{2}{|l|}{ Age } \\
\hline$\leq 10$ years & $130(81.2 \%)$ \\
\hline$>10$ years & $30(18.8 \%)$ \\
\hline \multicolumn{2}{|l|}{ Duration of Disease } \\
\hline$\leq 2.5$ years & $24(15 \%)$ \\
\hline$>2.5$ years & $136(85 \%)$ \\
\hline Parental Consanguinity & $122(76.3 \%)$ \\
\hline Standard Chelation Therapy & $47(29.4 \%)$ \\
\hline Diabetes & $41(25.6 \%)$ \\
\hline Hypothyroidism & $24(15 \%)$ \\
\hline
\end{tabular}

Mean $\mathrm{HbA} 1 \mathrm{C}$ level was $6.23 \pm 1.18 \% \mathrm{mg} / \mathrm{dl}$ and diabetes was noted in $41(25.6 \%)$ patients. (Table-II). Mean FT4 was $0.98 \pm 0.13 \mathrm{ng} / \mathrm{dl}$ and hypothyroidism was noted in $24(15 \%)$ patients (Table-III).

Table-II: Association of diabetes with different variables (n=160).

\begin{tabular}{|c|c|c|c|}
\hline \multirow[b]{2}{*}{ Variables } & \multicolumn{2}{|c|}{ Diabetes } & \multirow[b]{2}{*}{$\begin{array}{c}p- \\
\text { value }\end{array}$} \\
\hline & $\begin{array}{c}\text { Yes }(\mathrm{n} 1=41) \\
(25.6 \%)\end{array}$ & $\begin{array}{c}\text { No }(\mathrm{n} 2=119) \\
(74.4 \%)\end{array}$ & \\
\hline \multicolumn{4}{|l|}{ Gender } \\
\hline Male $(n=100)$ & $35(35 \%)$ & $65(65 \%)$ & \multirow{2}{*}{1.000} \\
\hline Female $(n=60)$ & $06(10 \%)$ & $54(90 \%)$ & \\
\hline \multicolumn{3}{|l|}{ Age (Years) } & \multirow{4}{*}{0.068} \\
\hline$\leq 10(\mathrm{n}=130)$ & $29(22 \%)$ & $101(78 \%)$ & \\
\hline$>10(n=30)$ & $12(40 \%)$ & $18(60 \%)$ & \\
\hline \multicolumn{3}{|c|}{ Disease Duration (Years) } & \\
\hline$\leq 2.5(\mathrm{n}=24)$ & $06(25 \%)$ & $18(75 \%)$ & \multirow{2}{*}{1.000} \\
\hline$>2.5(\mathrm{n}=136)$ & $35(26 \%)$ & $101(74 \%)$ & \\
\hline \multicolumn{3}{|c|}{ Number of Transfusions Per Month } & \multirow{3}{*}{ - } \\
\hline Up to $2(n=136)$ & $17(12.5 \%)$ & $119(87.5 \%)$ & \\
\hline$>2(n=24)$ & $24(100 \%)$ & - & \\
\hline \multicolumn{4}{|c|}{ Parental Consanguinity } \\
\hline Yes $(n=122)$ & $31(25.4 \%)$ & $91(74.6 \%)$ & \multirow{2}{*}{1.000} \\
\hline No $(n=38)$ & $10(26.3 \%)$ & $28(73.7 \%)$ & \\
\hline \multicolumn{4}{|c|}{ Standard Chelation Therapy } \\
\hline Yes $(n=47)$ & $6(12.8 \%)$ & $41(87.2 \%)$ & \multirow{2}{*}{0.017} \\
\hline No $(n=113)$ & $35(31 \%)$ & $78(69 \%)$ & \\
\hline
\end{tabular}

\section{DISCUSSION}

Thalassemias are a group of hereditary hemoglobinopathies often leading to life-threatening anemia and lifelong dependency on regular or intermittent blood transfusion for survival. It is highly prevalent in people of Indian subcontinent and Mediterranean 
region. The World Health Organization (WHO) has announced control of $\beta$-thalassemia as a priority, in developing world. ${ }^{10}$

Table-III: Association of Hypothyroidism with different variables $(n=160)$.

\begin{tabular}{|c|c|c|c|}
\hline \multirow[b]{2}{*}{ Variables } & \multicolumn{2}{|c|}{ Hypothyroidism } & \multirow[b]{2}{*}{$\begin{array}{c}p \text { - } \\
\text { value }\end{array}$} \\
\hline & $\begin{array}{c}\text { Yes }(\mathrm{n} 1=24) \\
(15 \%)\end{array}$ & $\begin{array}{c}\text { No }(\mathrm{n} 2=136) \\
(85 \%)\end{array}$ & \\
\hline \multicolumn{3}{|l|}{ Gender } & \\
\hline Male $(n=100)$ & $12(12 \%)$ & $88(88 \%)$ & \multirow{3}{*}{0.179} \\
\hline Female $(n=60)$ & $12(20 \%)$ & $48(80 \%)$ & \\
\hline \multicolumn{3}{|c|}{ Disease Duration (Years) } & \\
\hline$\leq 2.5(\mathrm{n}=24)$ & - & $24(100 \%)$ & \multirow{2}{*}{0.026} \\
\hline$>2.5(\mathrm{n}=136)$ & $24(17.6 \%)$ & $112(82.4 \%)$ & \\
\hline \multicolumn{3}{|c|}{ No. Of Transfusions Per Month } & \multirow{3}{*}{0.209} \\
\hline Up to $2(n=136)$ & $18(13.2 \%)$ & $118(86.8 \%)$ & \\
\hline$>2(n=24)$ & $06(25 \%)$ & $18(75 \%)$ & \\
\hline \multicolumn{4}{|c|}{ Parental Consanguinity } \\
\hline Yes $(n=122)$ & $20(16.4 \%)$ & $102(83.6 \%)$ & \multirow{2}{*}{0.447} \\
\hline No $(n=38)$ & $04(10.5 \%)$ & $34(89.5 \%)$ & \\
\hline \multicolumn{4}{|c|}{ Standard Chelation Therapy } \\
\hline Yes $(n=47)$ & $6(12.8 \%)$ & $41(87.2 \%)$ & \multirow{2}{*}{0.808} \\
\hline No $(n=113)$ & $18(16 \%)$ & $95(84 \%)$ & \\
\hline
\end{tabular}

After significant reduction in morbidity secondary to malnutrition and infectious diseases, health care professionals are focusing to reduce complications of patients of $\beta$-thalassemia. Highly equipped thalassemia setups are being established worldwide leading to increased life expectancy of these patients. Conversely this leads to a rising burden for relevant health-care services in developing countries like Pakistan, as regular blood transfusions and other treatment options (e.g, HLA matching and bone marrow transplantation) are not affordable by majority of patients. Many patients are poorly compliant with standard iron chelation therapy, its monitoring and regular screening of relevant complications. Keeping in view, preventive strategies could be effective as long term future approach. Effectiveness of a 20-year control program in Sardinia is statistically proved by significant reduction of their birth rate of thalassemia major from 1:250 live births to 1:4000. In 1995, 1999 and 2004, 296, 94 and $56 \beta$-thalassemia homozygote were born respectively. ${ }^{11}$ So formulating a control program and determining the underlying molecular defects in $\beta$-thalassemia is a chief prerequisite for such programs.12 In Pakistan prenatal diagnostic services are becoming available across the country and clinicians can guide their patients for screening and subsequent management. Genetic counseling, screening of population and prenatal diagnosis need to be focused to decide about future of affected pregnancies.
Moreover, early detection and effective management of relevant endocrinological complication can have long term positive impact on life of these patients by reducing the associated morbidities.

Total 160 patients of thalassemia were enrolled (according to inclusion criteria). Of these 160 study cases, $100(62.5 \%)$ were male patients while 60 (37.5\%) were female patients. A study conducted by Qurat-UlAin et al, has shown $65.7 \%$ male gender predominance in Thalassemia. ${ }^{13}$ A study by Safdar et al, has shown $57.2 \%$ male sex predominance. ${ }^{14} \mathrm{~A}$ study by Ejaz et al, from Karachi has also shown $54 \%$ male gender predominance. ${ }^{15}$ A study by Tehseen et al, has also documented $59 \%$ male sex predominance which is close to our study results. ${ }^{16}$

Mean age in our study cases was $8.58 \pm 1.98$ years (with minimum age 5 years and maximum age of 12 years). Mean age of the male patients was $8.63 \pm 1.99$ years while that of female patients was $8.50 \pm 1.97$ years $(p=0.689)$. Majority of our study cases i.e., 130 $(81.3 \%)$ were aged up to 10 years. A study conducted by Qurat-Ul-Ain et al, has also documented similar results. ${ }^{13}$ A study by Safdar et al, has also shown $9.40 \pm$ 5.66 years mean age, ${ }^{14}$ A study by Ejaz et al, from Karachi revealed that majority of thalassemia patients were aged less than 9 years. ${ }^{15} \mathrm{~A}$ study from by Tehseen et al, has documented $10.80 \pm 3.44$ years mean age which is in compliance with that of our study results. ${ }^{16}$

Mean duration of disease was $5.28 \pm 3.29$ years and $136(85 \%)$ had $>2.5$ years disease duration. A study by Ejaz et al, from Karachi has also revealed similar results. ${ }^{15}$ A study by Tehseen et al, has shown $8.23 \pm$ 3.15 years mean duration of illness which is higher than our study results. ${ }^{16}$

Out of $136(85 \%)$ had to undergo blood transfusion up to 2 times per month. Safdar et al. has reported similar pattern for blood transfusion in these children. 14 Parental consanguinity was positive in $122(76.3 \%)$ and only $47(29.4 \%)$ were taking standard chelation therapy. A study by Safdar et al has also revealed $72.8 \%$ parental consanguinity which is close to our study results. ${ }^{14}$

Mean level of $\mathrm{HbA1c}$ was $6.23 \pm 1.18 \% \mathrm{mg} / \mathrm{dl}$ and diabetes was noted in 41 (25.6\%) of our study cases. Mean FT4 was $0.98 \pm 0.13 \mathrm{ng} / \mathrm{dl}$ and hypothyroidism was noted in 24 (15\%) of our study cases. A local study by Ibrahim et al showed $13.8 \%$ hypothyroidism and $5.6 \%$ diabetes in children with thalassemia. ${ }^{5}$ A study done by Tehseen et al, has documented $25 \%$ diabetes which is consistent with our study results. ${ }^{16}$ Adil et 


\section{Endocrinopathies}

al, from Karachi has revealed that $29.4 \%$ thalassemic children had diabetes, $11.8 \%$ had hypothyroidism 4 . Satwani et al, from Karachi also documented 57.14\% children with thalassemia had endocrine complications which is consistent with our study results. ${ }^{17}$

A study conducted by Belhoul showed hypogonadism $(25.9 \%)$ as the most common endocrinopathy with diabetes mellitus (10.5\%), hypoparathyroidism $(10.5 \%)$ and hypothyroidism $(6.3 \%)$, which is not consistent with our results. ${ }^{18}$

\section{ACKNOWLEDGMENT}

We are grateful to the paramedical and administrative staff of paediatric department, CMH Multan, Pakistan for their dedication and contribution in the study.

\section{CONCLUSION}

Diabetes and hypothyroidism were commonly noted endocrinopathies in our study population among children having thalassemia. All doctors treating such patients should always screen such patients for early diagnosis and timely management in order to decrease burden of related morbidities and improve quality of life of these patients. An awareness campaign must be launched to create awareness among general public about early diagnosis and importance of screening for potential complications and role of effective chelation therapy in patients suffering from thalassemia.

\section{Conflict of Interest: None.}

\section{Authors' Contribution}

UT: Substantial contributions to conception and design, SM: Intellectual contribution to the conception, HMM: Drafting, analysis and acquisition of data, MMS: Theme and direct contribution of substance, LG: Revision and design contribution, AAA: Analysis, and interpretation of data.

\section{REFERENCES}

1. Bala J, Sarin J. Empowering parents of children with thalassemia. Int J Nurs Care 2014; 2(1): 22-25.

2. Dhirar N, Khandekar J, Bachani D, Mahto D. Thalassemia major; how do we improve quality of life? Springerpl 2016; 5(1): 1895.

3. Luo HC, Luo QS, Huang FG, Wang CF, Wei YS. Impact of genotype on endocrinal complications of children with Alphathalassemia in China. Sci Rep 2017; 7(1): 2948.
4. Adil A, Sobani ZA, Jabbar A, Adil SN, Awan S. Endocrine complications in patients of beta thalassemia major in a tertiary care hospital in Pakistan. J Pak Med Assoc 2012; 62(3): 307-310.

5. Ibrahim MN, Ansari SH, Shakoor I, Erum S, Hanif MI, Naqi Y, et al. Endocrine Complications in Thalassemic Patients and Its Relation to Genotype. Pak Paed J 2017; 41(3): 125-130.

6. Warncke K, Konrad K, Kohne E. Diabetes in Patients with Bthalassemia or other hemoglobinopathies - analysis from the DPV Database. Klin Padiatr 2016; 228(06/07): 307-312.

7. Sharmin T. Thyroid status in children with transfusion dependent Hb-E $\beta$-thalassaemia. Mymensingh Med J 2018; 27(2): 348357.

8. Yousuf M. Compliance with deferoxamine therapy and thyroid dysfunction of patients with $\beta$-thalassemia major in Syria. Hemoglobin 2019; 43(3): 218-221.

9. Upadya SH. Thyroid function in chronically transfused children with beta thalassemia major: a cross-sectional hospital based study. Int J Pediatr 2018; 5(1): 9071213.

10. Weatherall DJ. The inherited diseases of hemoglobin are an emerging global health burden. Blood 2010; 115(22): 4331-4336.

11. Karimi M, Jamalian N, Yarmohammadi H, Askarnejad A, Afrasiabi A, Hashemi A. Premarital screening for $\beta$-thalassemia in Southern Iran: options for improving the program. J Med Scr 2007; 14(1): 62-66.

12. Saqib H, Tahir $S$, Mushtaq A. Molecular epidemiology of $\beta$ thalassemia in Pakistan: far reaching implications. Int J Mol Epidemiol Genet 2011; 2(4): 403-408.

13. Qurat-ul-Ain LA, Hassan M, Rana SM, Jabeen F. Prevalence of $\beta$-thalassemic patients associated with consanguinity and antiHCV-antibody positivity-a cross sectional study. Pak J Zool 2011; 43(1): 29-36.

14. Safdar S, Mirbahar A, Sheikh MA, Taseer IH, Mustafa A, Ali Z, et al. Economic burden of thalassemia on parents of thalassemic children: a multi-centre study. Pak J Med Res 2017; 56(3): 68-72.

15. Ejaz MS, Baloch S, Arif F. Efficacy and adverse effects of oral chelating therapy (deferasirox) in multi-transfused Pakistani children with beta-thalassemia major. Pak J Med Sci 2015; 31(3): 621-625.

16. Tehseen Q, Bari A, Bano I, Jabeen U, Rathore AW. Frequency of impaired glucose tolerance in beta thalassemia major patients. Pak Paed J 2017; 41(3): 131-136.

17. Satwani H, Raza J, Alam M, Kidwai A. Endocrinal complications in thalassemias: frequency and association with serum ferritin levels. Pak Paed J 2005; 29(3): 113-119.

18. Belhoul KM, Bakir ML, Saned MS, Ahmed MA, Khaled M, Ali $\mathrm{T}$, et al. Serum ferritin levels and endocrinopathy in medically treated patients with $\beta$ thalassemia major. Ann Hematol 2012; 91(7): 1107-1114. 